\title{
Guest Editorial Preface
}

\section{Special Issue on Democratizing Research for Social Justice: The Role of Digital Technologies and Audio-Visual Tools}

\author{
Alejandra Boni, INGENIO (CSIC-UPV), Universidad Politécnica de Valencia, Valencia, Spain \\ Gynna Millan, Queen Mary University of London, London, UK
}

The use of digital technologies and audiovisual tools in social research is, more than a trending topic, opening new potentials to the way knowledge is produced, shared and disseminated (Pink, 2013; Stanczak, 2007; Pauwels, 2010). However, there is a growing critical literature that also highlights shortcomings and risks that deploying these tools could pose to researchers and communities in the field (Banks, 2007; Gubrium et al, 2014; Mitchell, 2011; Kleine, 2013) The special issue we introduce here, arise from the question we, as guest editors, were concerned ourselves with: how are digital technologies and audiovisual tools in research contributing to social justice? We were particularly interested in hearing from researchers who are focusing their work on issues related to social justice in either the global South or North.

The four papers selected are great contributions to answer that question and help us make the case for two key ideas, we consider essential, to be understood within this frame. The first, we need an understanding of what social justice is, which will be the end, while digital technologies and audiovisual tools will be the means to reach it. The second, we need to position ourselves in a particular perspective of knowledge production, which needs to be aligned with the idea of social justice. Again, if the end is social justice, then, which is the way (the means) in which knowledge could be generated? We are aware of our strongly normative standpoint, but if we want to tackle the big challenges we are facing today (e.g. growing inequalities, unsustainability, lack of democracy, etc.) we need to be explicitly normative.

How are we going around those two ideas? For the first one, we have chosen to understand social justice from a particular development theory: the human development and capability approach. For the second, we want recognise different forms of knowledge and different ways of knowing by which people across the globe run their lives and provide meaning to their existence. As we will see in this editorial, the latter is a condition of the former. If we assure cognitive justice (De Sousa Santos, 2006), we are contributing to human development and, finally, to social justice. In other words, as Sousa Santos (2006) states: social justice is not possible without cognitive justice.

The following three sections of the editorial are devoted to explain these two core ideas and the connection between them. After it, we will present the four papers that are proposing practical ways to use digital technologies and, particularly, audiovisual tools, to contribute to cognitive justice. The four papers touch upon a different range of technologies and methodologies: Sammia Poveda's paper is showing an example of digital literacy in Campinas (Brasil) using a participatory action research 
(PAR) approach based in Paulo Freire's method of concientization. Gioel Gioacchino and Kirsten Williams' contribution explores photovoice and participatory video as methods especially appealing to young researchers. Alejandra Boni, Monique Leivas, Teresa De La Fuente and Sergio Belda-Miquel' paper examines the use of participatory video with grassroots organisations in Valencia (Spain). Sara Calvo and Andrés Morales' shows how applied video research can create new knowledge that provide visibility to the practice of social and solidarity economy.

Also, two of those papers (Poveda and Boni et al.) are making original contributions to the way in which different elements of the human development and capability approach can be used to analyze participatory processes conducted with digital and audiovisual tools.

\section{THE HUMAN DEVELOPMENT AND CAPABILITY APPROACH}

How development has been understood and defined has been a major area of controversy. Implicit values assumptions and associated policy responses are linked to the nature of the definitions employed and theories of development proposed (Summer and Tribe: 2008). Human development and capability approach can be understood as part of the liberal egalitarian theories of development (McCowan, 2015). These theories do not take as a starting point the eradication of capitalist modes of production and the free market, although they do require a significant tempering of its workings and practice in accordance with social justice. In opposition to some versions of socialism, they also assert the primacy of individual liberty - guarding against the subordination of the individual to the collective; while in opposition to post-structuralist thought they retain faith in the possibility of a universal morality and the assumption that concrete steps towards improvements in practice can be made.

In fact, the human development and capability approach understood the development of society as a normative concept that differs from economic growth or social change. The standard definition of the dimensions of human development by the United Nations Programme for Development (UNDP) includes: 1) empowerment, understood as the expansion of the capabilities of people (real opportunities to achieve valuable ends) and the expansion of valuable functionings (valuable purposes achieved), and participation; 2) the equitable distribution of basic skills; 3) sustainability; and 4) the freedom of people to enjoy their opportunities and achievements (Boni and Gasper, 2012).

As we see in the above definition, human development encompasses the expansion of capabilities and functionings of people. Sen (1999) define capabilities as the substantive freedoms of people to lead the kind of life they value. Sen indicates that worthwhile development means that individuals have the freedom and the opportunity (capability) to lead the kind of lives they want to lead, to do what they want to do, and to be who they want to be. Once they actually have these substantive opportunities, they may choose to implement those options that they value most, which is the idea of functioning. Martha Nussbaum presents ten central capabilities for the functioning of human beings, which she argues, are fundamental requirements for a decent life, and which together, meet a minimum degree of social justice. A society that does not guarantee these capabilities for all of its citizens, at an appropriate level, cannot be considered a just society, whatever its level of affluence (Nussbaum, 2000).

\section{PAR as a Way to Contribute to Cognitive Justice}

Post-colonial theorists such as Thuwai Smith (2012) argue that research is a site of significant struggle 'between the interests and ways of knowing of the West and the interests and ways of knowing of the other'. While we might generally claim that research aims to add value to and benefit society (and we have many good examples of this), research also 'exists within a system of power' (Smith, 2012, p. 226), and in contemporary times, within globalization flows and neo-liberal higher education policies (Boni and Walker, 2016).

If we want to locate research in a human development frame, we first need to attend to epistemic challenges and to "cognitive justice" (De Sousa Santos, 2006, p.19). He proposes that different ways 
of knowing across the globe have been neglected and that this is a matter of a 'cognitive injustice' and the failure by dominant knowledges to recognize the different ways of knowing by which people across the globe run their lives and provide meaning to their existence. The university, he argues, could contribute towards 'cognitive justice' by recognizing and valuing epistemological diversity. Through 'cognitive justice' we may arrive at a truly global social democracy in which there is recognition of the multiplicity of social practices and experiences of the world, but there will be no global social democracy if there is no democracy between forms of knowledge.

This transformation of knowledge is further elaborated in his 'ecology of knowledge' (2009). Knowledge, he argues, exists only as a plurality of ways of knowing. The possibilities and limits of understanding and action of each way of knowing can only be grasped to the extent that each way of knowing offers a comparison with other ways of knowing. The comparison is difficult because the relations among ways of knowing are haunted by an asymmetry, which is not only epistemological but also political. De Sousa Santos therefore, proposes an ecology of knowledge, which is contrary to the "epistemological fascism that amounts to violent destruction or concealment of other ways of knowing" (2009, p. 116).

As a way to contribute to the ecology of knowledge, we want to make the case for PAR. It is part of the Action Research (AR) tradition, which share the following key characteristics first articulated by Reason and Bradbury in the Sage Handbook of Action Research (2001):

$A R$ is emergent and developmental. It concerns practical issues and human flourishing. Its modality is primarily participative and democratic, working with participants and towards knowledge in action (Reason and Bradbury, 2001, p. 7)

As O'Leary (2014) points out, AR has some key elements that differentiate it from other research traditions: 1) It is grounded in real problems and real life situations and it seeks to understand these problems and implement solutions within the context; 2) It pursues action and knowledge, as enacting change is seen not as the end product of knowledge, but valued as a source of knowledge in itself. Nevertheless, knowledge production is understood as a disciplined process, ensuring credibility and rigour; 3) AR calls for collaboration between researchers, practitioners and any other interested stakeholders. Without key stakeholders as part of the research process, outsiders are limited in their ability to build rich and subtle understanding, or implement sustainable change. 4) AR is understood as a cyclical process that takes shape as knowledge emerges and works through a series of continuous improvements in cycles that, generally, involve some variation in observation, reflection, planning and action.

We can place PAR under the umbrella of AR, as it shares the same characteristics, albeit with a more explicit emphasis on the goals of emancipation and liberation (Boni and Frediani, 2017). Orlando Fals Borda, a Colombian sociologist, was the first person to use the term 'participatory action research' in the late 1970s (Hall 2005). Fals Borda and many of his colleagues in Colombia and elsewhere in Latin America had made the decision to use their intellectual skills and connections to strengthen political movements struggling for democratic institutions at that time (Hall 2005). An additional important influence for PAR was Paulo Freire and his understanding of the research process. In his Pedagogy of the Oppressed (1970), Freire proposed investigating 'generative themes,' which are relevant for people's lives:

To investigate the generative theme is to investigate people's thinking about reality and people's action upon reality, which is their praxis. For precisely this reason, the methodology proposed requires that the investigators and the people (who would normally be considered objects of that investigation) should act as co-investigators (p. 106).

The methodology of 'conscientização' (similar but more political than problematisation, see Poveda's paper in this issue) is crucial to co-research these generative themes, as it 'introduces or begins 
to introduce women and men to a critical form of thinking about their world' (Freire, 1970; 2005, p. 104). Freire, Fals Borda and other Latin American thinkers have been influential in developing this understanding of PAR that resonates with the following definition by Freire (in Smith et al, 1997):

Those promoting participatory action-research believe that people have a universal right to participate in the production of knowledge, which is a disciplined process of personal and social transformation. In this process, people rupture their existing attitudes of silence, accommodation and passivity, and gain confidence and abilities to alter unjust conditions and structures (p. xi).

\section{PAR and the Human Development and Capability Approach}

Based in an emancipatory and democratic understanding of PAR (Boni and Frediani, forthcoming 2017), we now want to bring the human development and capability approach into the analysis and explore what further insights this framework can offer. Firstly, we can argue that participation that happens in a PAR process can contribute to expand capabilities of participants (see Boni et al paper in this issue).

Moreover, the knowledge produced through a PAR process can assume different forms of representation (written, oral, visual, etc.), can be of different kind (practical, experiential, etc.) and can be produced by different people and groups. From a human development and capability perspective, it is crucial to include the perspectives of multiple actors, paying special attention to voices with fewer opportunities to be heard.

A second element to analyse the knowledge axis is the alignment with the core values of human development: well-being, participation and empowerment, equity and diversity and sustainability, as we have proposed above. Our last point is the action part of PAR. We can ask ourselves what kind of action could bring about social justice? According to the capability approach, we could argue that the PAR process could expand the opportunities space of the participants through public deliberation moments that take place through PAR (or even after). Public deliberation is one of the core ideas of the human development and capability approach and we have seen how our understanding of PAR is fully aligned with it. Thus, we can expect that, during PAR, several deliberative moments may occur between the participants. However, beyond what may happen during the process (in so far as we can clearly define where and when the PAR ends), we should aim to influence changes in the public sphere aligned with the human development and capability approach (Boni and Frediani, in press).

Habermas (1989) refers to the public sphere, a communicative space open to reasoned arguments and contending values. However, assuming that this communicative space is essential, we would like to aspire to a more transformative impact of PAR. The debate on the deepening democracy issue presented by Gaventa (2006) could be useful to illustrate what we have in mind. Gaventa argues that the critical challenge for democracies nowadays is how to deepen their inclusiveness and substance, especially in terms of how citizens engage within democratic spaces to create more just and equitable states and societies. In Gaventa's view, democracy may be seen as constantly contested and under construction; the issue is not replicating one version of democracy, as a standard set of institutions and practices, but to construct and deepen democracies, which may work differently in different places, and to find the most effective entry points for doing so, based on the local contexts. At the same time, while recognising the diversity of forms of democracy, such diversity does not preclude more universal commitment to the core values of democracy as highlighted by Sen (1999). Under this perspective, a relevant contribution of a PAR process can be to facilitate the deliberative entry points Gaventa refers to, in local, national and global spheres (Boni and Walker, 2016).

\section{Digital Technologies and Audio-Visual Research Tools for Social Justice}

We live in a digital world! that is what many tend to believe when access to digital technologies and digital literacy is in place, which allow people to take part of the currently sprawling knowledge- 
based economy and urban societies. However, the first paper in this special issue, presented by Sammia Poveda, set out reminders that access to digital is far from even worldwide and that, if urban communities were to increase development, then, digital inclusion programmes need to be put in place. But not only for individuals to be able to technically use them, but for them to be able to conclude by themselves, if they are actually meaningful or not to their own realities. Poveda develops a theoretical framework that combines the capability approach and the critical pedagogy as described by Paulo Freire, to analyse a digital inclusion project undertaken in Campinas, Brazil.

By using the capability approach, Poveda clearly defines where the focus of development should be, and that is, on the individual and her freedoms. In line with this, Poveda uses the concept of "adaptive preferences" to explain a series of conditions that are at play and that could limit an individual's ability to self-choose her goals (in this case, in using ICTs) and subsequently, to achieve them. Even though, the capability approach has been influential in policy making internationally, she also highlights critical drawbacks such as the difficulty of the theory to be put into practice and the lack of attention to overcome the effects of 'adaptive preferences'. This is where Poveda intertwines critical pedagogy's key propositions to go further in her analysis. To undertake her research, Poveda uses the "Problem-Posing Education" method, considered in the group of tools under Participatory Action Research (PAR), to engage with students and staff of the Committee of Democratization of Information in Campinas. Poveda's main findings reflect the great potential that digital skills have to enhance people's agency and collective power. However, she also stresses aspects such as fear from some students, to challenge the social constraints and being unwilling to accept change and adjusting themselves instead. Poveda concludes that access to ICTs alone not necessarily translates into capabilities of individuals to overcome social constrains. Besides, digital inclusion practices need to move away from focusing on delivering just technical skills as they do not support students to become more aware of the root causes of social constrains that are limiting their abilities.

The second paper by Gioel Gioacchino and Kirsten Williams opens the appetite for digital technologies and audio-visual research tools within the participatory paradigm of PAR. Gioacchino and Williams combine their academic work with their lived experience as researchers in the organisation "Recrear International" - a youth led international practice that aims at exploring new participatory and tools for research- to illustrate lessons learned, potentials and challenges in the deployment of participatory techniques. They go further in exploring photovoice and participatory video as methods, which are, due to their audio-visual nature, more appealing to young researchers. They argue that the ever-increasing access to digital and technological devices are opening new opportunities for PAR methodologies to be creatively rethought and adapted. However, they also highlight the influence that attitude and intentions behind research design has in the adoption of these new methods, as they are not "automatically participatory or action oriented". The authors contribute new ways of approaching research with young people and establish an interesting dialogue with PAR literature to suggest that new spaces of connections can be created and new learning environments can actually lead to transformation. But one may ask, transformation of what? for whom? and why? They frame their reflections in the idea that 'development', beyond economic growth, more fundamentally, relates to "the process through which individuals deepen their connections with themselves, each other, their community and their world".

In tune with the use of the capability approach, human development and audiovisual tools for research, the third paper by Alejandra Boni, Monique Leivas, Teresa De La Fuente and Sergio BeldaMiquel is concerned with the role of grassroots innovation in promoting more equitable and sustainable development. To undertake their exploration, they adopt participatory video as a methodological tool under PAR to navigate the work of two social organisations operating in Valencia, Spain. The first is concerned, at a micro level, with raising awareness of fuel consumption practices, and at a macro level, with the generation and adoption of new energy models. The second centers its focus on changing food production and consumption practices. Through occupying deteriorated private land in the city, members of the organisation develop activities such as urban gardening, with the aim to 
bring neighbors together to participate and interact. By using participatory video, the authors argue, not only the PAR component allows participants to reflect more about their own practice, but also, they get to disseminate their social message in an engaging and attractive way that video as a means of creative communication allows. Boni et al. introduce a tridimensional framework to analyse both, the process and the product of the participatory video and to reveal (or not) its potential as a tool for human development innovation. They pay special attention to the type of knowledge co-created, the participation in the communicative spaces generated, and, the agency and capabilities that could have been expanded in participants. They also use the final video narratives - which are made by members of the organisations themselves-to identify remarks that touch on core human development values.

The final paper in this issue by Sara Calvo and Andres Morales make the case for the use of visual methods in the field of organisation and management studies, particularly in the area of 'Social and Solidarity Economy' (SSE). Using their own experience working with video to explore motivations, actors, impacts, challenges, etc. of these initiatives in more than fifteen countries around the world, Calvo and Morales, make a timely contribution to the methodological aspects and challenges that deploying visual tools entail for the 21 st Century social researcher. They argue that by using video to gather data allows for more "analytical passes" than other forms of data collection. When watching back the images, researchers and those involved in SSE initiatives can "re-awaken" memories that open possibilities for reflection and contributions during the process. Besides, with the boom of the so-called digital revolution, video is transforming into a powerful, creative tool to disseminate findings that can reach worldwide audiences, increasing the likelihood of impact of research beyond the communities involve. The authors also flag out the importance of evaluating the objectivity of the research questions so themes and theories support them and keep the video data concise. Ethical issues such as privacy and ownership have always been a sensitive topic that discourage many social researchers from using audio-visual tools, however, digital is challenging the way researchers can play around those critical limitations. Another contribution from the authors is a step-by-step plan for researchers who have are willing to experiment but are not familiar with the neither the methodology nor the technicalities. Finally, Calvo and Morales demonstrate that visual research -and videos as products of this practice-carefully combined with written case studies, is a powerful method and tool to "promote social justice by empowering organisation which are part of the 'Cinderella' economy".

\author{
Alejandra Boni \\ Gynna Millan \\ Guest Editors \\ IJEP
}




\section{REFERENCES}

Banks, M. (2007). Using Visual Data in Qualitative Research. London: Sage Publications. doi:10.4135/9780857020260

Boni, A., \& Frediani, A. A. (in press). Expanding Capabilities through Participatory Action Research. In Chiappero-Martinetti, Osmani and Quizibash (eds.) The Cambridge Handbook of the Capability Approach. Cambridge: Cambridge University Press.

Boni, A., \& Gasper, D. (2012). Rethinking the quality of universities - How can human development thinking contribute? Journal of Human Development and Capabilities, 13(3), 451-470. doi:10.1080/19452829.2012.6 79647

Boni, A., \& Walker, M. (2016). Global Human Development: Theoretical and Empirical Insights for Social Change. London: Routledge.

De Sousa Santos, B. (2006). The Rise of the Global Left: The World Social Forum and Beyond. London: Zed Books.

De Sousa Santos, B. (2009). A Non-Occidentalist West? Learned Ignorance and Ecology of Knowledge. Theory, Culture \& Society, 26(7-8), 103-125. doi:10.1177/0263276409348079

Freire, P. (1970). Pedagogy of the Oppressed. London: Continuum.

Freire, P. (1997). Forward. In Smith, et al. (Eds.), Natured by Knowledge. New York: The Apex Press.

Gaventa, J. (2006). Triumph, Deficit or Contestation? Deepening the 'Deepening Democracy' Debate (IDS Working Paper 264).

Gubrium, A. C., Hill, A. L., \& Flicker, S. (2014). A situated practice of ethics for participatory visual and digital methods in public health research and practice: A focus on digital storytelling. American Journal of Public Health, 104(9), 1606-1614. doi:10.2105/AJPH.2013.301310 PMID:23948015

Habermas, J. (1989). The Structural Transformation of the Public Sphere: An Inquiry into a Category of Bourgeois Society(trans. T Burger).Cambridge, MA: The MIT Press.

Hall, B. (2005). Reflections on participatory research from 1970-2005. Convergence, 38(1), 5-24.

Kleine, D. (2013). Technologies of choice?: ICTs, development, and the capabilities approach. Cambridge, MA: MIT Press.

McCowan, T. (2015). Theories of Development. In T. McCowan \& E. Unterhalter (Eds.), Education and International Development: An Introduction (pp. 31-48). London, New York: Bloomsbury Academic.

Mitchell, L. M. (2006). Child-centered? Thinking critically about childrens drawing as a visual research method. Visual Anthropology Review, 22(1), 60-73. doi:10.1525/var.2006.22.1.60

Nussbaum, M. (2000). Women and Human Development. Cambridge: Cambridge University Press. doi:10.1017/ CBO9780511841286

O’Leary, Z. (2014). The Essential Guide to Doing Your Research Project (2nd ed.). London: Sage.

Pauwels, L. (2010). Visual sociology reframed: An Analytical synthesis and discussion of visual methods in social and cultural research. Sociological Methods \& Research, 38(4), 545-581. doi:10.1177/0049124110366233

Pink, S. (2013). Doing Visual Ethnography (3rd ed.). London: Sage.

Reason, P., \& Bradbury, H. (2001). Sage Handbook of Action Research: Participative Inquiry and Practice. London: Sage Publications.

Sen, A. (1999). Development as Freedom. New York: Knopf.

Smith, T. (2012). Decolonizing Methodologies (2nd ed.). London: Zed Books.

Stanczak, G. (Ed.). (2007). Visual Research Methods: Image, Society and Representation. Thousand Oaks, CA: Sage Publications. doi:10.4135/9781412986502

Summer, A., \& Tribe, M. (2008). International Development Studies: Theories and Methods in Research and Practice. London: Sage Publications. doi:10.4135/9781446279397 